\title{
EDITORIAL
}

\section{Investigar para educar en diseño y otras urgencias de la Educación Artística}

\author{
Research to Educate in Design and other Emergencies in Art
} Education

Ricard HUERTA. Universitat de València (España). ricard.huerta@uv.es

Ricardo DOMÍNGUEZ. Universitat de València (España). ricardo.dominguez@uv.es

Ana Mae BARBOSA. Universidade de São Paulo (Brasil).

anamaebarbosa@gmail.com

Resumen: La enseñanza del Diseño en el sistema educativo español resulta peculiar frente a otros modelos como el anglosajón, donde no existe una diferenciación tan drástica entre estudios de Bellas Artes (Fine Arts) y Diseño (Design). En un contexto cambiante, acelerado por los ritmos que impone el uso de las tecnologías, la pervivencia de las tradicionales separaciones entre las especialidades vinculadas a las artes supone un obstáculo para la innovación educativa y para dar respuesta a las necesidades formativas que la sociedad reclama. Una de las claves para redefinir el nuevo espacio es el impulso de la investigación educativa. En este sentido, las "VIII Jornadas Internacionales de Investigación en Educación Artística" promovidas el Grupo CREARI de Investigación en Pedagogías Culturales (GIUV2013-103), la EASD de Valencia y el Instituto de Creatividad e Innovaciones Educativas de la Universitat de València se plantean como un encuentro académico en el cual abordar los diferentes aspectos que preocupan al sector. Unimos los conceptos de investigación y educación en el ámbito del Diseño para de gestionar propuestas de futuro. Junto a otros artículos, presentamos un dossier sobre "Investigar y educar en diseño". En esta demanda por una mayor presencia de las artes en la educación, el proyecto de innovación educativa "Second Round: Arte y Lucha en Secundaria" de la Universitat de València presenta la iniciativa "Second Round Cerámica" un evento académico y formativo que contará con la colaboración de varios institutos de secundaria y de la EASC de Manises. Nos hacemos eco también de la delicada situación en la que se encuentra la educación artística en Brasil, donde las medidas 
legislativas aprobadas por el Gobierno determinan la supresión de su obligatoriedad en la Enseñanza Media. Todo ello nos reafirma en la necesidad de aunar esfuerzos para contribuir desde diferentes instancias a la visibilidad y puesta en valor de las enseñanzas artísticas en el ámbito educativo.

Palabras clave: educación artística, investigación, diseño, arte, formación del profesorado, educación secundaria.

\begin{abstract}
Education in Design in Spain is different from the American or English model, where there is no such drastic differentiation between Fine Arts and Design Studies. In a changing context, accelerated by the new rhythms imposed by technologies, the traditional separation of Art specialties is an obstacle to educational innovation. The key to redefining the new scenario is to promote Educational Research. Promoted by the EASD Valencia, CREARI Research Group in Cultural Pedagogies (GIUV2013-103) and the Institute of Creativity and Educational Innovations of the University of Valencia, the "VIII International Conference Research in Art Education" combine the concepts of research and education in the field of Design to manage future proposals. Along with other articles, we present a dossier on "Research and Design Education". We call for a greater presence of the arts in education. The project "Second Round: Art and Struggle in Secondary" presents the initiative "Second Round Ceramics", an academic and training event that will count with the collaboration of several Secondary Schools and the Manises EASC. Finally, the situation in Brazil is delicate, after the suppression of Art Education in the Middle School. All of this reaffirms that we need to join efforts to contribute to the visibility and enhancement of Artistic Education.
\end{abstract}

Keywords: Art Education, Research, Design, Art, Teachers Training, Secondary School.

El sistema educativo español no contempla la enseñanza del Diseño en las propuestas universitarias, ni tampoco se incluye esta formación como parte de la oferta de Educación Secundaria. La enseñanza del Diseño, en sus múltiples variantes (de moda, textil, gráfico, de escenografía, de interiores, de producto, etc.), se ubica en un entramado de especialidades que se ha venido denominando "Enseñanzas Artísticas Superiores". Esto supone admitir que la enseñanza del diseño no es universitaria, pero tampoco podemos afirmar que está ubicada completamente fuera del panorama universitario, ya que no estamos hablando de educación secundaria, con lo cual, los estudios de diseño se integran en una especie de "limbo administrativo" del que forman parte también los estudios que se imparten en los Conservatorios Superiores de Música, los Conservatorios Superiores de Danza. Esta situación anómala, e incluso "alegal", propicia alteraciones administrativas que se contradicen, como por ejemplo el hecho de que las EASD Escuelas de Arte y Superiores de Diseño (nomenclatura oficial de este tipo de centros) pueden implantar titulaciones de máster, pero no están en condiciones de conceder títulos de grado. De hecho, en 
los últimos años se ha generado un enfrentamiento de tipo legal entre las EASD y las Facultades de Bellas Artes, precisamente debido a esta polémica situación. Lejos de solucionar el problema, desde las altas instancias de la administración del Estado no hay previsiones de mejorar el embrollo, y mientras tanto la terminología "Diseño" sigue dando pie a equívoco, ya que se usa en numerosos ámbitos, tanto universitarios como no universitarios, y de manera muy especial en los centros de gestión privada, ya que el diseño gráfico, especialmente cuando se trata de entornos informáticos o de procesos online, es un ámbito de formación y de proyección laboral muy apetecible por parte de los jóvenes estudiantes. Está en juego el futuro de miles de adolescentes que desean abrirse camino en el diseño de entornos online o de la creación de videojuegos, así como la formación de generaciones enteras de estudiantes en edad universitaria a quienes les gustaría formar parte de los procesos virtuales alternativos que avanzan aceleradamente en constante evolución. En este sentido, queremos destacar nuestra firme apuesta por la enseñanza pública. Tanto las EASD como las Facultades de Bellas Artes, y muy especialmente los responsables de los centros públicos, deberían iniciar una estrategia conjunta encaminada a normalizar la situación de los estudios de Diseño, dando así un ejemplo de unión y fuerza, tanto hacia los responsables políticos (que son quienes en última instancia podrían mejorar la situación legal y administrativa), como de cara a las nuevas generaciones de estudiantes que se matricularán en sus respectivos centros.

El modelo anglosajón no diferencia de forma drástica entre los estudios de Bellas Artes (Fine Arts) y los estudios de Diseño (Design). De hecho, las escuelas o facultades de artes, tanto en el Reino Unido como en los Estados Unidos, y también en la mayoría de los países de la antigua Commonwealth, incorporan de manera efectiva los estudios de Diseño en los mismos centros de Artes, en cuyos recintos, además, se incluyen las especialidades de Artes Escénicas y de Música. Un ejemplo representativo de este sistema sería la Winchester School of Art, que está integrada en la University of Southampton. Aquí tenemos una muestra muy reveladora de lo que supone incorporar los estudios de Diseño en el mismo recinto universitario donde se forman los artistas visuales, los estudiantes de música, y quienes se matricularon en artes escénicas o en cine. Al unir todos estos potenciales se crea un entorno muy propicio al intercambio, de manera que los estudiantes de música no ven su especialidad como una rama ajena al resto de formaciones artísticas. Un dato revelador a tener en cuenta es que a la titulación de especialista en educación se la denomina "Art and Design Postgraduate Certificate in Education (PGCE)", un título universitario que permitirá a los futuros profesionales ejercer la docencia tanto en artes visuales como en diseño. Otro caso llamativo de la coherencia con la que se desenvuelven estos aspectos en el ámbito anglosajón es que una de nuestras publicaciones más emblemáticas se llama International Journal of Art and Design Education IJADE. En esta prestigiosa y muy recomendable revista encontramos artículos centrados tanto en la educación en artes visuales como en la educación en diseño. Lo más llamativo es que cuando se trata de estudios en los que se aborda la figura del profesorado o bien las problemáticas de los entornos educativos, 
observamos que no se genera una distinción clara entre alumnado o profesorado por su adscripción al diseño o bien a las artes visuales. Teniendo en cuenta el interés de nuestras autoridades por integrarnos en las dinámicas del idioma inglés, una lengua en la que se enmarca la investigación internacional, podrían tomar nota también del modelo que domina el panorama anglosajón de la educación en artes visuales y diseño, de ese modo evitaríamos delimitaciones legales infructuosas o limitaciones académicas que estrangulan cualquier tipo de avance. A estas alturas, todavía tenemos pendiente aclarar en qué lugar se puede formar a los futuros profesionales del cine. El tradicional encajonamiento de corte académico que delimita los ámbitos tradicionales de las materias, las asignaturas y las especialidades concretas, pervierte cualquier posibilidad de innovación en lo que se refiere a enseñanzas artísticas. La gastronomía ha tomado las riendas de la innovación en el terreno de las artes y el diseño, pero todavía sigue sin encajar en un sistema de valores académico tradicional que sigue separando artificiosamente la pintura del dibujo, la escultura de las instalaciones, o la música de los audiovisuales. Necesitamos un ambiente educativo y artístico más poroso y receptivo, un cruce de caminos generoso y empático con las nuevas realidades, un espacio de transiciones en el que no exista la obsesión por separar en clave arcaica cada una de las especialidades históricas, ya que los nuevos ritmos que están imprimiendo tanto las tecnologías como los usos de los públicos van mucho más allá de la segregación por especialidades. En esta línea de actuación, desde EARI apostamos por integrar la educación en diseño en el entramado universitario.

\section{Investigar y educar en diseño}

Con el espíritu integrador que nos caracteriza, lo cual supone también reforzar la unión de colectivos (en Valencia hemos sido pioneros tanto en la gestación de organizaciones de educadores y mediadores en museos y patrimonios AVALEM como en la del profesorado de dibujo de secundaria AVPD), desde EARI lanzábamos hace un año la propuesta de editar en el presente número de nuestra revista un dossier titulado "Investigar y educar en diseño". Se trata de una iniciativa novedosa, lo cual llama la atención porque la investigación sobre educación en diseño no es una prioridad, ni de las autoridades, ni de los colectivos profesionales implicados, ni del mundo académico en general. Esta situación debe mejorar, y por ello presentamos este dossier en el que participan especialistas de diferentes ramas del diseño, profesorado que está investigando sobre la importancia de incluir la reflexión en sus tareas educativas. Queremos con este dossier llamar la atención hacia esta parcela de la educación en artes (nosotros no diferenciamos entre artes y diseño), de manera que se visibilice dicha realidad, para avanzar en un territorio que urge normalizar, tanto en lo académico como en todo lo relativo a investigación. Diseñar es investigar, es encontrar soluciones a problemas nuevos, o replantear los problemas de siempre con preguntas novedosas. Quien diseña investiga. Y quienes educan en diseño deben también investigar sobre sus acciones pedagógicas. ¿Qué diferencia substancial puede haber en la relación entre el profesorado y el alumnado 
de materias como "Volumen" o "Diseño de Producto"? O mejor aún, ¿hasta qué punto podemos separar actualmente la enseñanza del "Dibujo" de la enseñanza del "Diseño de videojuegos" o del "Diseño gráfico"? ¿A alguien se le escapa que Andy Warhol, uno de los artistas más influyentes de la segunda mitad del siglo XX, se formó como ingeniero y desarrolló su obra inicialmente como diseñador gráfico? Llegados a este punto, podríamos entrar en un juego de nomenclaturas, ya que somos conscientes que el término inglés "design" (diseño) también se utiliza en el idioma italiano para diferenciarlo de "disegno" (dibujo). No favorece demasiado la situación el hecho de que existan museos del diseño, diferenciándose en muchos sentidos de los que tradicionalmente conocemos como museos de artes visuales. Y sigue perpetuándose de manera insistente la división entre artistas y artesanos ("arts and crafts"). Los prejuicios se van acumulando de forma exagerada, hasta el extremo de haber optado por un eufemismo como lo es la denominación EASD para nombrar lo que antiguamente se llamaban de modo oficial Escuelas de Artes y Oficios. Así las cosas, y esperando que se avance en positivo, desde EARI pensamos que la clave está en la investigación. Por tanto, animamos al profesorado de diseño a presentar sus trabajos de investigación a nuestra revista, con el deseo de apoyar un entramado integrador, mucho más acorde con las perspectivas de futuro.

En paralelo al impulso que queremos dar a la investigación sobre Educación en Diseño, este año 2017 organizamos desde la Universitat de València las "VIII Jornadas Internacionales de Investigación en Educación Artística" en colaboración con la EASD de Valencia. Bajo el título "Investigar y educar en diseño", estas jornadas se han planteado como un encuentro académico en el cual se abordarán los diferentes aspectos que preocupan al sector. El modelo que seguirán las jornadas es de contraponer ideas entre especialistas, de manera que las ponencias serán conversaciones entre educadores, investigadores y diseñadores. Los diálogos se establecerán entre pares, reforzando así el encuentro desde los diferentes entornos. La mayoría de ponentes serán mujeres, lo cual supone asumir el peso y la hegemonía del alumnado y el profesorado femenino en los centros de arte y diseño. Entre las invitadas como ponentes destacamos la presencia de Marisa Gallén, Amaia Arriaga (Universidad Pública de Navarra), Amparo Alonso-Sanz (Universitat de València), Sara Barquero (CEU), Giovanna Ribes, Anna Majó (EINA Barcelona), Sofía Rodríguez (Museo de Artes Decorativas de Madrid) o Sara Colaone (Universidad de Bolonia). La Escuela de Arte y Superior de Diseño de Valencia, el Grupo CREARI de Investigación en Pedagogías Culturales (GIUV2013-103) y el Instituto de Creatividad e Innovaciones Educativas de la Universitat de València, con la colaboración de Las Naves Centre d'Innovació (Ajuntament de València) promueven estas Jornadas que consolidan los trabajos realizados por nuestra universidad en los últimos años en relación a la investigación en Educación Artística. Nos anima el interés por renovar las posibilidades que aporta la investigación y la enseñanza del Diseño en los entornos de aprendizaje, planteando la posibilidad de generar momentos propicios para difundir el conocimiento del diseño, especialmente en el ámbito educativo superior. Propiciamos un espacio de reflexión sin perder de 
vista el espíritu de colaboración entre entidades que tradicionalmente estamos distanciadas. Posibilitamos así la participación de relevantes investigadores universitarios y diseñadoras de prestigio, responsables institucionales, docentes, y todas aquellas personas que tanto desde la perspectiva educativa como desde los diferentes niveles educativos, la universidad y el mundo de la empresa desean analizar la situación actual de la investigación y la educación en el diseño. Esta es una propuesta muy innovadora, ya que no se había abordado anteriormente con esta perspectiva integradora. Aunamos así los conceptos de investigación y educación en el ámbito del Diseño, con el fin de revisar lo que se ha hecho hasta ahora en esta materia, y sobre todo gestionar propuestas de futuro.

Las VIII Jornadas Internacionales de Investigación en Educación Artística "Investigar y educar en Diseño" están planteadas desde la perspectiva del Horizonte 2020 (H2020), el Programa Marco de la Comisión Europea para la investigación y la innovación, ya que se trata de una actividad basada en el interés por la innovación. Al reunir a representantes de la sociedad civil, el mundo de los negocios y el mundo académico, ofrecemos excelencia científica, promoviendo la investigación de alto nivel. También es un reto social, ya que enfrenta el desafío de problemáticas y miradas con carga social. Alentamos la participación de diferentes estamentos a través de una nueva estrategia que permite un enfoque amplio, rompiendo cualquier obstáculo a la creación de un espacio real de conocimiento, investigación e innovación. Como siempre decimos, la clave está en la investigación, y por tanto, urge contemplar la investigación en educación del diseño como una modalidad más de la investigación en educación artística.

En el número 8 de la revista EARI se presentan un total de trece artículos, cinco de ellos forman parte del dossier titulado "Investigar y educar en diseño", a través del cual pretendemos impulsar y dar visibilidad a la investigación que se está llevando a cabo en este ámbito.

El compromiso social desde la educación artística es una cuestión clave que aparece de manera destacada en algunos de los artículos de este número. Así, Alba Braza presenta la experiencia del taller didáctico Diálogos y otras ausencias a través de la obra de Pepe Espaliú, realizado en el IVAM con motivo de la exposición dedicada al artista Pepe Espaliú. A través del taller los participantes, estudiantes de grado de magisterio y de grado y posgrado en bellas artes, reflexionan sobre cuestiones como el cuerpo, el deseo, la enfermedad, la disidencia, la homosexualidad, el estigma, la ausencia y la soledad. Se reivindica de este modo la figura del educador artístico en su práctica profesional y compromiso social.

Nuria Rey, Laura Delgado-Guillén, Jorge Fernández-Cedena y Silvia SainzRabanal presentan el proyecto de arte comunitario y educación artística realizado a iniciativa de la organización Solidarios para el Desarrollo en colaboración con la Facultad de Bellas Artes de la Universidad Complutense de Madrid en el Centro 
Penitenciario Madrid IV. En este artículo se expone el desarrollo del taller, los resultados y las conclusiones extraídas del taller realizado entre los meses de febrero y junio de 2015, partiendo de un programa de actividades que tiene como objetivo conectar el interior y el exterior del centro por medio de estrategias artísticas. La segunda fase del proyecto, realizada un año después, viene recogida en el artículo de Jorge Fernández-Cedena. En el mismo se pone de manifiesto la necesidad del trabajo conjunto con los educadores sociales, unificando objetivos y desarrollando propuestas comunes, como herramienta de apoyo para conseguir, en algunos casos, la reeducación y reinserción social de los internos en prisión.

Ana María Montserrat Bajac comparte una investigación sobre el museo como entorno para la inclusión educativa. En su artículo relata la experiencia del Museo Escolar del Centro Educativo los Laureles en Paraguay, un lugar donde la comunidad educativa ha ido aportando progresivamente diferentes objetos que nos remiten a su identidad como pueblo paraguayo y como colectivo, coexistiendo de este modo el patrimonio material con las narrativas, herencias y vínculos emocionales.

El artículo de Sara Victoria Carrasco y Rosario García-Huidobro, partiendo de los desafíos sociales, culturales, políticos y económicos de la sociedad actual, recupera la noción de posmodernidad como enfoque que invita a pensar sobre la posición fluctuante y en constante movimiento de la manera de ser docentes y articular las relaciones pedagógicas en el contexto de la educación artística. En otro artículo de la revista, Rosario García-Huidobro nos presenta una investigación a partir del estudio narrativo en la vida de cuatro maestras chilenas, donde se reflexiona cómo éstas conforman sus saberes desde sus conflictos e incertidumbres. A través de estos relatos se manifiesta cómo la falta de herramientas pedagógicas y de experiencia didáctica, el lugar del no saber, se puede transformar en una oportunidad para aprender.

Josefina Abara realiza una reflexión sobre los límites difusos entre el rol del artista y el rol del educador. Desde la situación problemática de la escasa integración de la educación en artes visuales en la educación formal, plantea una metodología para la elaboración de proyectos desde el posicionamiento del artista educador. Supone también una reivindicación hacia una mayor interdependencia entre arte y educación que aproveche el potencial transformador y crítico del arte en la educación.

Elke Castro presenta una investigación realizada entre el alumnado de la ESO que opta por continuar con su formación académica preuniversitaria dentro de las enseñanzas artísticas El análisis de los casos seleccionados permite conocer conceptos relativos a los elementos del fenómeno artístico, arte, artista, obra de arte, público, percepción y técnica o procedimiento, que componen el universo simbólico de estos jóvenes, evidenciando la importancia que tiene el entorno en la configuración de dichas estructuras. El desvelamiento de las mismas supone un elemento clave para una lectura profunda del aula por parte del docente. 
Ya dentro del dosier sobre "Investigar y educar en diseño", José Ramón Andújar presenta la experiencia desarrollada en la Escuela Superior de Diseño de Valencia a partir de la utilización del origami como recurso didáctico en la formación de diseñadores en la asignatura de Espacio y Volumen. Se describe de qué modo su implementación supuso una revisión y renovación profunda de la asignatura, así como su incidencia en los procesos de proyectación, fomentando el desarrollo de la creatividad y la visión espacial.

Francesc Aracil en su artículo realiza una revisión de los planes de estudios de las enseñanzas del diseño en el contexto español desde la década de los 60 hasta el marco que establece la LOE, en el que pasan a incluirse en el nivel 2 del Marco Español de Cualificaciones para la Educación Superior (MECES), equivalentes al título universitario de grado. En este recorrido analiza el cambio de estatus del dibujo como materia pedagógica, y cómo la incorporación de nuevas materias y el creciente uso de programas informáticos ha reducido progresivamente la presencia del dibujo en la evolución de los estudios de diseño en general.

$\mathrm{M}^{\mathrm{a}}$ Encarna Palazón realiza una reflexión sobre las relaciones entre la fotografía realizada con las cámaras móviles y las representaciones del cuerpo humano. $\mathrm{Su}$ análisis aborda cuestiones como el placer visual o voyeur, las representaciones del cuerpo humano, la evolución tecnológica de la fotografía y la incidencia que la incorporación de los dispositivos móviles ha tenido en las narrativas visuales generadas por los mismos.

Desamparados Pardo-Cuenca presenta una investigación sobre la aplicación de métodos de trabajo colaborativos en el desarrollo de proyectos de diseño de moda. Bajo una metodología basada en el estudio de casos, la investigación analiza la experiencia llevada a cabo en un grupo de estudiantes españoles para, posteriormente, comparar los resultados obtenidos con el estudio de un caso italiano que trabajó con el método de codiseño propuesto utilizando el mismo enfoque. Los resultados obtenidos evidencian cómo la práctica de metodologías de participación en el diseño con un enfoque de codiseño refuerza el aprendizaje y la creatividad, y abren nuevas vías de reflexión sobre la didáctica del diseño.

Nieves Torralba y José Martínez Escutia presentan la génesis del diseño curricular de la asignatura Diseño Básico, de la especialidad de Diseño de Moda, a partir de la nueva estructura derivada del nuevo plan curricular de los Estudios Superiores de Diseño de Moda. El artículo expone en detalle su propuesta didáctica basada en un enfoque interdisciplinar que trata de aunar la experiencia de taller con aspectos de la cultura visual.

Por último EARI 8 recoge dos entrevistas. En la primera, realizada por Ricard Huerta a la profesora Chiara Panciroli, docente e investigadora en el Departamento de Ciencias de la Educación "Giovanni Maria Bertin” de la Universidad de Bolonia, 
HUERTA, DOMÍNGUEZ \& BARBOSA / Investigar para educar en diseño y otras urgencias de la Educación

se recogen aspectos de su trayectoria profesional y reflexiones sobre la educación artística, la formación de docentes y el futuro de la universidad. Se destaca también su vinculación con la educación patrimonial con iniciativas como la creación y el desarrollo del MOdE (Museo Officina dell'Educazione), una apuesta online que está demostrando la gran capacidad que tiene la educación patrimonial cuando se usan adecuadamente las tecnologías.

En la segunda, Ma Dolores Soto-González entrevista a Teresa Torres de Eça, presidenta de APECV (Associação de Professores de Expressão e Comunicação Visual) e InSEA (International Society For Education Throught Art). Esta entrevista nos acerca a labor llevada a cabo desde esta institución así como el modo en que se puede articular la necesaria relación entre museo, escuela y universidad.

\section{Sigue latente la problemática de la Educación Artística en Secundaria}

La Educación en Diseño, a pesar del desajuste legal, debería formar parte del entramado educativo que necesitamos construir (con miras más amplias) para generar una educación de lo visual en todas las etapas vitales. La trayectoria de cualquier individuo necesita contemplar una cercanía efectiva con el conocimiento y el disfrute de las imágenes, y por extensión de las artes visuales, desde la Educación Infantil, Primaria y Secundaria hasta llegar a la Universidad. Para ello necesitamos concienciar a los poderes políticos, pero también a los colectivos que actualmente tenemos la responsabilidad de ejercer la docencia, especialmente en secundaria y universidad, pero también en las EASD y en los centros y academias privadas de artes (Rueda, 2015). Todas las personas que nos dedicamos a educar en artes tenemos la responsabilidad y la obligación de impulsar acciones para potenciar la presencia de la enseñanza de la imagen en las diferentes etapas de formación. Por ello entendemos que es muy importante organizar encuentros. Valoramos de forma positiva la creación de la plataforma 09+ Federación Estatal del Profesorado de Dibujo, lo cual posibilita canales de comunicación directo entre el Ministerio y los representantes del profesorado de Dibujo de Secundaria. Desde la Federación se evidencia la necesidad social de una educación coherente con los tiempos actuales para formar a la ciudadanía en lo visual, mediante un itinerario formativo riguroso desde Infantil hasta Bachillerato. El sistema debe mirar al futuro y considerar la importancia del aprendizaje de la imagen en todas las etapas, ya que el nuevo espacio de comunicación requiere de una ciudadanía formada en un perfil científico, humanístico y artístico. Los representantes de la Federación se reunieron con el director general de educación y le hicieron entrega de un documento con las peticiones que se acordaron en el "I Encuentro Estatal de Profesorado de Dibujo" celebrado en la Universidad Autónoma de Madrid el 27 de Mayo de 2017.

En esta misma línea de actuaciones de urgencia para reclamar una mayor presencia de las artes en la educación, el proyecto de innovación educativa "Second Round: 
Arte y Lucha en Secundaria" tiene previsto realizar su cuarta iniciativa apostando por el fomento de la Cerámica. El que hemos denominado "Second Round Cerámica" se convierte así en un nuevo escenario para integrar los esfuerzos de profesorado, alumnado y equipos directivos de centros valencianos en los que se van a desarrollar las distintas acciones reivindicativas que promueve "Second Round". La tradición ceramista valenciana es milenaria, y contamos con centros específicos: la Escuela de Arte y Superior de Cerámica de Manises y la de l'Alcora. Es a través de la EASC de Manises que se va a articular el "Second Round Cerámica", un evento académico y formativo que contará con la colaboración de varios institutos de secundaria. Conscientes del desconocimiento que existe de este tipo de centros, queremos activar una mayor difusión de esta realidad, animando al profesorado de secundaria a realizar acciones concretas para informar al alumnado de esta posibilidad formativa de futuro. Como siempre, la clave está en la investigación, y serán las creaciones cerámicas innovadoras las que propiciarán una realidad mucho más resuelta en el panorama del diseño. Llama la atención que la mayoría del alumnado de la EASC de Manises procede de otras nacionalidades, de manera que disponemos de espacios adecuados y profesorado muy preparado para formar a gente que proviene de numerosos países, fallando por tanto la presencia de estudiantes autóctonos. Con el "Second Round Cerámica" damos un paso más en la integración del diseño en el conjunto de las modalidades que ofrece la educación artística. Y además, como siempre, potenciamos la investigación.

\section{El dilema de las artes en la Educación Secundaria (Enseñanza Media) en Brasil}

La profesora Ana Mae Barbosa, eminente personalidad de la Educación Artística tanto en su país de origen como en el resto del mundo, nos informa de la delicada situación que se está viviendo en Brasil a causa de las decisiones del gobierno actual, que está eliminando las enseñanzas artísticas de los programas educativos. Nos aliamos con Ana Mae para reivindicar la necesidad de reforzar las enseñanzas artísticas, una problemática que afecta tanto a un país como Brasil, emergente potencia mundial que tantos avances ha generado en materia de educación artística, como al resto de países del panorama occidental.

El actual Gobierno de Brasil, por decreto, a través del subterfugio "medida provisional", sin oír la sociedad, y con una masiva campaña de propaganda pagada y engañosa en los canales de televisión, decidió acabar con la obligatoriedad de la educación artística en la Enseñanza Media (Educación Secundaria).De nuevo Brasil copia el sistema implantado en los Estados Unidos, operando reducciones comprometedoras para el aprendizaje de la juventud en nombre de la economía y del ahorro para el erario público. La Dictadura Militar del Brasil (que duró desde 1964 hasta1983) ya copió el sistema norteamericano, minimizando la calidad, cuando hizo que el arte fuese materia obligatoria en Educación Primaria y Secundaria, con el objetivo de enmascarar humanísticamente el exceso tecnológico de la reforma 
educativa impuesta que pretendía profesionalizar a los adolescentes de secundaria. El proceso reductivo del modelo americano para las economías de los países pobres creó la figura absurda del "profesor polivalente" que con dos años de formación debería enseñar Música, Artes Plásticas, Artes Escénicas, y Dibujo Geométrico a partir del quinto año de Primaria y en lo que hoy llamamos Educación Secundaria. Aquello no funcionó, y las grandes universidades advirtieron inmediatamente acerca del absurdo epistemológico de querer formar "multiespecialistas leonardodavincis" en el siglo XX. Ahora la cosa es peor, si cabe, ya que están retirando de la Enseñanza Secundaria la obligatoriedad de la Educación Artística, ampliada gracias a la lucha de los arte/educadores reunidos en la Federación de Arte/Educadores de Brasil (FAEB), que en abril de 2016 logró que se aprobase en el Senado la obligatoriedad de materias como Música, Teatro, Artes Visuales y Danza.

En los Estados Unidos el alumnado de secundaria elige un cierto número de disciplinas entre una enorme oferta de materias que tiene cada centro. Entre las disciplinas ofertadas están todas las áreas de Artes. El inglés es obligatorio como idioma, pero para cada semestre se ofrecen diferentes cursos con aspectos peculiares, de modo que el alumnado elige qué tipo de curso quiere realizar. No es obligatorio elegir artes, pero sí que es obligatorio que cada centro de secundaria disponga de oferta adecuada de todas las artes. Resulta evidente que el gobierno de Brasil pretende imitar esta perspectiva, aunque bajo una mirada reductora, ya que provocará una eliminación progresiva de las artes en secundaria, minimizando así la importancia de la educación artística en el sistema educativo.

En Estados Unidos, en la década de 1990, se descubrió que entre el alumnado que durante 10 años había tenido las mejores notas en el test SAT, equivalente al ENEM, el $100 \%$ del total encuestado había realizado alguna disciplina de artes. Se pasó entonces a estudiar la enseñanza de las artes en relación con la transferencia cognitiva. Las preguntas eran: ¿Es transferible a otras disciplinas qué se aprende y cómo se aprende en las materias de artes? ¿El desarrollo mental que proporcionan las artes es aplicable al modo en que se aprende las otras disciplinas? James Catterall (2002) dedicó gran parte de sus investigaciones a demostrar que las artes desarrollan la cognición del individuo, pudiendo aplicarse a otras áreas del conocimiento. Llegó a la conclusión de que las artes desarrollan la inteligencia medida por el test QI que se centra sólo en la inteligencia racional. En cuatro de sus investigaciones se probaba que la transferencia de aprendizaje de las artes visuales es extensible a otras áreas. Estas investigaciones demostraban que el estudio del dibujo aumenta la calidad de organización de la escritura. También que el razonamiento sobre el arte desarrolla la capacidad de razonar sobre imágenes científicas, o que el análisis de imágenes propicia la capacidad de lectura más sofisticada y la interpretación de textos o la interrelación de diferentes textos. Quedaba por tanto demostrado que la formación en artes visuales desarrolla la lectura comprensiva, una de las conclusiones de las cuatro investigaciones que llevó a cabo Catterall. Entre las consecuencias positivas de la experiencia de las artes en el comportamiento cognitivo de los jóvenes de 
secundaria destaca: una mayor comprensión de la lectura oral de textos y del discurso oral en general; el aumento de la interacción comunicativa; la capacidad de escribir con eficiencia; aumento de habilidades de resolución de conflictos; una mayor concentración de pensamiento; habilidades para comprender las relaciones sociales; mayor capacidad para comprender problemas complejos y emociones; mayor compromiso; más habilidad de interpretación de textos no relacionados; mejor disposición y capacidad para desarrollar estrategias para la resolución de problemas. En las investigaciones sobre Artes Integradas (que no debemos confundir con la perversa "polivalencia"), que disponen de profesorado especialista pero en donde se trabaja interdisciplinariamente, se han comprobado avances individuales y colectivos en: confianza en sí mismo; mejora del auto-concepto; capacidad de asumir riesgos; concentración de atención; perseverancia; empatía con los demás; auto-iniciación al aprendizaje; persistencia en tareas difíciles; aprendizaje de autor; habilidades de colaboración; liderazgo; evasión reducida; mayores aspiraciones educativas; mejora de habilidades de pensamiento de orden superior. La lista de transferencia cognitiva de la música a otras áreas no artísticas de conocimiento es importante también e incluye desarrollo en matemáticas y en percepción espacial y espacio/temporal.

A causa del escaso interés del alumnado norteamericano de Educación Primaria y Secundaria hacia las ciencias, se creó en los Estados Unidos el sistema interdisciplinario STEM, es decir, la interrelación entre Ciencias, Tecnología, Ingeniería y Matemáticas. Sin embargo, las investigaciones no mostraron la mejora esperada en la enseñanza de las ciencias. La investigadora y profesora Georgette Yakman consiguió mejores resultados incluyendo las artes. Desde que desarrolló su trabajo, el STEM se transformó en STEAM, sistema que incluye Ciencias, Tecnología, Ingeniería, Artes (también Diseño) y Matemáticas. Al haber incorporado las Artes se comprueba que la imaginación y los procesos de creación se intensifican. También verificaron que las Artes se vuelven importantes cultural y comunicativamente, facilitando el aprendizaje de las otras áreas involucradas en el sistema. Lo que ahora está en juego es que en el conjunto del STEAM, las artes no se conviertan en un mero trabajo de ilustración. Todo esto nos lleva a la conclusión de que eliminar las artes de la Educación Secundaria (y por tanto, eliminar este importante aspecto del conocimiento en la formación de los adolescentes) reduce la posibilidad del desarrollo de habilidades importantes en otras disciplinas, además de las artes. Por otro lado, ¿qué otra disciplina desarrolla lo que es específico de las artes? ¿Cuál es la disciplina en el currículo que desarrolla específicamente la percepción y la discriminación visual? Esto es propio de las artes visuales y ninguna otra más. ¿Cuál es la que prepara para la lectura de la imagen? Las artes visuales. El discurso visual requiere un acercamiento a la significación de la imagen, lo cual convierte este ámbito del conocimiento en un imperativo de la contemporaneidad.

En nuestras rutinas cotidianas estamos conviviendo con imágenes, creándolas, difundiéndolas, aprendiendo con ellas. La lectura de las imágenes de los medios, de 
la publicidad y del arte ejercita la conciencia acerca de lo que aprendemos a través de la imagen. Por su parte, en la escuela, la lectura de la obra de arte prepara al gran público para la recepción del arte de manera que pueda originar un verdadero diálogo entre creación artística y públicos. Otro aspecto importante del arte en la educación en nuestros días es el hecho de reconocer que el conocimiento de la imagen es de fundamental importancia no sólo para el desarrollo de la subjetividad, sino también para el desarrollo profesional. Un gran número de trabajos y profesiones están directa o indirectamente relacionados con la imagen. No podremos preparar un buen diseñador gráfico que no posea verdadera información sobre Historia del Arte. No solamente en el caso de diseñadores gráficos, sino otros muchos profesionales podrían ser más eficientes si conociesen y practicasen artes. Si estas personas hubiesen desarrollado su capacidad analítica a través de la interpretación de los trabajos artísticos en su contexto histórico podrían incorporar a sus respectivas profesiones la sabiduría que requiere un buen conocimiento de las imágenes, incorporando en tal consenso las imágenes del arte. El conocimiento crítico de cómo los conceptos visuales, sociales e históricos aparecen en el arte, de qué manera han sido percibidos, redefinidos, rediseñados, distorsionados, descartados, reapropiados, reformulados, justificados y criticados en sus procesos constructivos, ilumina la práctica del arte, incluso cuando esta práctica es meramente comercial.

Si bien hemos utilizado argumentos de orden objetivo resultado de investigaciones para demostrar la importancia de la enseñanza de las artes, también debemos tener en cuenta la educación emocional, aunque este aspecto no interesa a los políticos responsables de la educación en un país como Brasil. Conviene destacar la importancia de las experiencias con artes en la adolescencia, una edad difícil y complicada, un momento de cambios hormonales, corporales, de modo de pensar y sentir, de inicio de autonomía en la vida privada y en la sociedad, de cruce de límites. El lenguaje de las artes articula la cognición a través de la integración del pensamiento racional, afectivo y emocional en una escuela a la que sólo interesa el lenguaje discursivo y científico de las evidencias. Las generaciones que han sido educadas en las escuelas a través de las artes ya están llenando las exposiciones, los cines y los teatros. Actualmente la enseñanza interrelaciona el hacer arte, la lectura de la obra de arte o de la imagen y la contextualización de lo que se hace y de lo que se ve (lo que Ana Mae ha desarrollado como propuesta denominada Abordaje Triangular). Como resultado de este planteamiento iniciado hace 25 años, los centros culturales ya no son exclusivos de las élites. Jóvenes de entornos desfavorecidos están actualmente disfrutando de las artes porque tuvieron buenos profesores de artes en las escuelas públicas. Este territorio ganado lo vamos a perder si desaparecen las artes de la Educación Secundaria. Desde aquí hacemos un llamamiento a los artistas para que hagan campaña y exijan la presencia de las artes en la formación de las próximas generaciones. 
HUERTA, DOMÍNGUEZ \& BARBOSA / Investigar para educar en diseño y otras urgencias de la Educación

\section{Referencias bibliográficas}

Barbosa, A. M. (2015a). Redesenhando o desenho: educadores, política e história. Sao Paulo: Editorial Cortez.

Barbosa, A. M. (2015b). La imagen en la enseñanza del arte. México: UANL.

Catterall, J. S. (2002). The Arts and the Transfer of Learning.En R. Deasy (ed.) Critical links: Learning in the arts and student an academic and social development. Washington: Arts Education Partnership, pp. 151-157.

Moraes, P.(2017).STEAM: Arte e Design no Currículo do Ensino Médio. Tesis doctoral. São Paulo: Universidade Anhembi Morumbi.

Rueda, P. (2015). Entornos de educación artística no formal: estudio de casos en academias de arte privadas en Valencia. Tesis doctoral. València: Universitat de València. 